\title{
About Improving Collection Efficiency for Industrial Plate-Type Electrostatic Precipitator
}

\author{
Gabriel Nicolae Popa \\ Department of Electrotechnical Engineering and Industrial Informatics \\ "Politechnica" University of Timisoara, \\ Revolutiei str., no.5, 331128, Hunedoara, Romania \\ gabriel.popa@fih.upt.ro
}

Keywords: collection efficiency, dust, plate-type electrostatic precipitator, power supply, section.

\begin{abstract}
Plate-type electrostatic precipitators are the largest and most used industrial dusts control, most applications are in the production of electricity (thermoelectric power plants). In many industrial applications, plate-type precipitators have three sections and silicon-controlled rectifier power supplies type. Although, the collection efficiency obtained by these type of precipitators are more than $95 \%$, most of the dust particles with diameter less than $10 \mu \mathrm{m}$ remain un-collected. To improve the collection efficiency different electrical and/or mechanical options can be used. To improve the collection efficiency of industrial plate-type precipitators, the paper presents two practical options. The first solution would be replacing the power supplies - silicon-controlled rectifier - with other special power supplies (intermittent power supplies, high frequency power supplies) depending on the dust resistivity; the second solution would be to add a new section at precipitator - an expensive solution, usually the last. The technological and electrical sizes, simulated and measured, are presented for the proposed solutions.
\end{abstract}

\section{Introduction}

The electrostatic precipitators have been used in industry applications, for almost a century to controlling pollution with dust particles [1].

For de-dusting of the gases resulted from the coal's burning in the boilers' firing places - in the thermoelectric power plant, to each boiler is attached an plate-type electrostatic precipitator (ESP) composed, usually, by three or four sections for separating the dust from the waste gases.

The sections are placed successively (one after another). Each section can be sectioned in two zones, to increase the reliability of precipitator. The ESP itself is the part of the electric de-dusting installation in which takes place the ionization and separation of the dust particles from gases $[2,3]$.

This type of ESP is used to remove pollutants from large flow gas (hundreds of thousands $\mathrm{m}^{3} / \mathrm{h}$ ) [4].

Table 1.

Typical values of some parameters for precipitators from thermoelectric power plants [5]

\begin{tabular}{|l|c|}
\hline Distance between collecting plates $[\mathrm{cm}]$ & $20-30$ \\
\hline The average speed of the gas inside precipitator $[\mathrm{m} / \mathrm{s}]$ & $1.2-2.4$ \\
\hline The specify collection surface $\left[\mathrm{m}^{2} /\left(\mathrm{m}^{3} / \mathrm{s}\right)\right]$ & $45-1000$ \\
\hline The form coefficient $\mathrm{k}_{\mathrm{F}}[-]$ & $1-1.5$ \\
\hline The average migration speed of dust particles $[\mathrm{cm} / \mathrm{s}]$ & $3.05-15.2$ \\
\hline Sections number $[-]$ & $4-8$ \\
\hline Corona power/gas flow $\left[\mathrm{W} /\left(\mathrm{m}^{3}{ }_{\mathrm{N}} / \mathrm{h}\right)\right]$ & $59-295$ \\
\hline Current density at collecting plates $\left[\mathrm{mA} / \mathrm{m}^{2}\right]$ & $107-860$ \\
\hline Surface of collecting electrodes on one section $\left[\mathrm{m}^{2}\right]$ & $465-7430$ \\
\hline Corona power/gas flow $\left[\mathrm{W} /\left(\mathrm{m}^{3}{ }_{\mathrm{N}} / \mathrm{h}\right)\right]$ & $59-295$ \\
\hline
\end{tabular}


The efficiency of ESPs depends on voltages waveform and amplitude, type of power supply, current control, geometry of electrostatic precipitators, type of discharge wires, gas composition, particles distribution, gas flow, temperature, and pressure, and particles velocities distribution.

To improve the efficiency of ESPs electrical and/or mechanical methods can be used. In the case of electrical improvements, different types of power sources can be used e.g.: for large particles and high dust resistivity a high-frequency D.C. power supply, and for fine particles intermittent supplies and pulsed power supplies. The collection efficiency of ESP increases, generally, with the sections number. Adding a new section, for ESP with three sections, it is a solution that must be analyzed practically and economically (adding a new section may be a too expensive solution) $[2,3,6,7]$.

\section{Collection Efficiency of the ESPs}

Collection efficiency is the most important technological parameter of ESPs. This indicates the degree of retention of dust particles $[4,5,8]$. Basically, the collecting efficiency is calculated by:

$$
\eta=\frac{\mathrm{q}_{\text {in }}-\mathrm{q}_{\text {out }}}{\mathrm{q}_{\text {in }}} \cdot 100=\left(1-\frac{\mathrm{q}_{\text {out }}}{\mathrm{q}_{\text {in }}}\right) \cdot 100,
$$

where $q_{\text {in }}\left[\mathrm{mg} / \mathrm{m}^{3}{ }_{\mathrm{N}}\right]$ and $\mathrm{q}_{\text {out }}\left[\mathrm{mg} / \mathrm{m}^{3} \mathrm{~N}\right]$ represents the concentration of dust from the input and the output. Another important parameter is dust penetration. Calculation of dust particles penetration through precipitator can be computed with:

$$
p=100-\eta \text {. }
$$

It was determined experimentally that the precipitator, even if it is not powered with electricity, constitutes a mechanical barrier to gas with dust. Thanks to turbulence and precipitator design, dust particles come into contact with the collecting electrodes, which have certain porosity, and some of the particles will be attached to these surfaces. After the dust layer thickness grows, when his weight exceeds the value of the force grip, the dust falls in bunkers, a part of the dust being reentrainment in gas movement. On the pilot precipitator, without power supply, a significant efficiency collection of dust was obtain $\left(\eta_{\mathrm{m}}=20-40 \%\right.$, where $\eta_{\mathrm{m}}$ is the mechanical collection efficiency of ESP) [2].

\section{Improving Collection Efficiency Using Different Types of Voltage Wave Shapes}

The type of the power supplies of ESPs sections is one of the most important factor that causes a high collection efficiency of dust particles.

For the most power supplies, to control the Corona power, the line voltage is regulated by a silicone-controlled rectifier (SCR type) through phase control, before it is applied to the primary stage of the high voltage transformer. The high voltage transformer (has some windings ratio $n$ ) to desired high voltage, to obtain Corona discharge and then rectified by a high voltage silicon bridge rectifier. This voltage (usually, up to $60-80 \mathrm{kV}$ ) is applied to a precipitator section without additional filtering. This type of energization is often used in practice, and has been used in the last three decades for normal dust resistivity $10^{6}-10^{9} \Omega \cdot \mathrm{cm}[3]$.

For intermittent energization it is used the same electrical equipment used in classical energization. The difference is the automatic voltage equipment that suppresses a number of halfcycles of the primary current delivered to the high voltage transformer. Suppression is obtained by not firing the thyristors in the respective half cycles. This suppression of current pulses is called degree of intermittence. The intermittent energization can be used to collect medium dust resistivity $10^{9}-10^{11} \Omega \cdot \mathrm{cm}[2]$.

Another type of power supply is pulse energization, has a short duration high voltage pulses superimposed on a continuous voltage. The pulse of high voltage is between 1 and $100 \mu$ s and the pulses frequency is between 1 and $400 \mathrm{~Hz}$. One can obtain approximately $100 \mathrm{kV}$ amplitude. In principle, there are two main circuits to supply the precipitator sections: one based on switching at low potential and one based on switching at high potential. The pulse energization is used to collect high dust resistivity between $10^{11}-10^{13} \Omega \cdot \mathrm{cm}[9]$. 
The development of fast electronic switching devices (fast-thyristors, IGBT, and so on) has caused the development of power supplies of precipitators. Basically, the power supply has the main components: the primary three-phase rectifier bridge, the D.C. intermediary filter to slow down the voltage ripples, and the primary inverter, with different configuration and components, with switching frequency in the range from $\mathrm{kHz}$ up to $50 \mathrm{kHz}$. The raise-up single phase transformer at high voltage and frequency is made from ferrite toroidal core. In the secondary stage of the raise-up transformer it is connected the secondary high voltage and high frequency rectifier that is used to obtain the continuous voltage in precipitator section. The problems of interrupting power supply (arc and re-establishing current of the precipitator) are reduced by operation at high frequency (e.g. $10 \mathrm{kHz}$ ) and the voltage on the precipitator section is almost continuous (with low ripples). The recovery time, to recharge the precipitator can be better controlled with the smaller time steps increments. High frequency power supplies are used experimentally in the last years for normal and medium dust resistivity [2,9].

Over the years, mathematical models have been developed for the physical phenomena which take place at the precipitator operation. There are various performance softwares that allow modelling the precipitators operation. One of the best mathematical models is implemented in the software ESPVI $4.0 \mathrm{w}$ (Windows version) [5,8].

To analyze the influence of the shape of the voltage supply applied on sections it have achieved many simulations (continuous voltage from a high-frequency switching power supplies, full-wave rectifier voltage from classical power supply that are used often in the present, and intermittent power supply, for two degrees of intermittence: 3 and 7) - Figs.1.a-d.

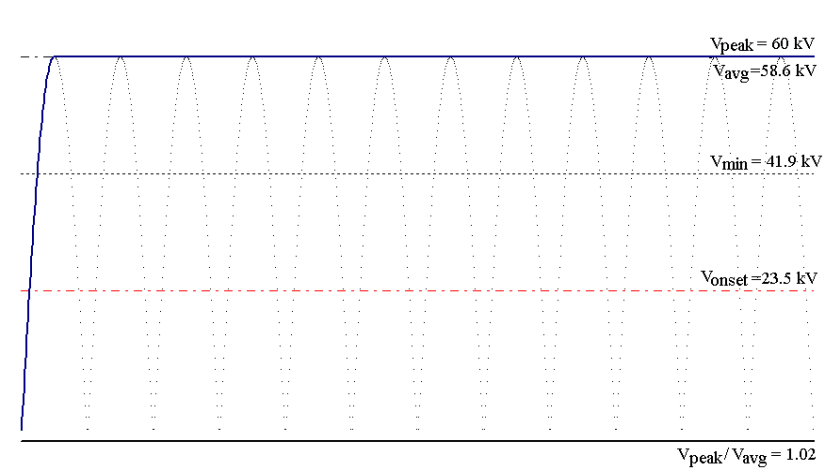

a.

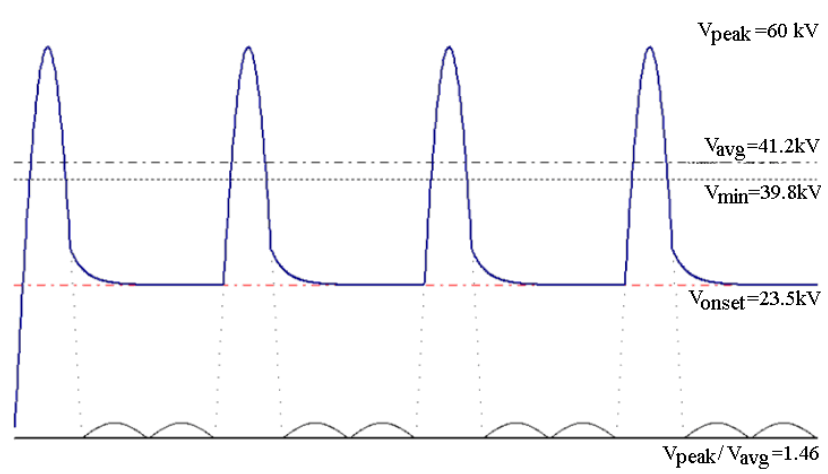

c.

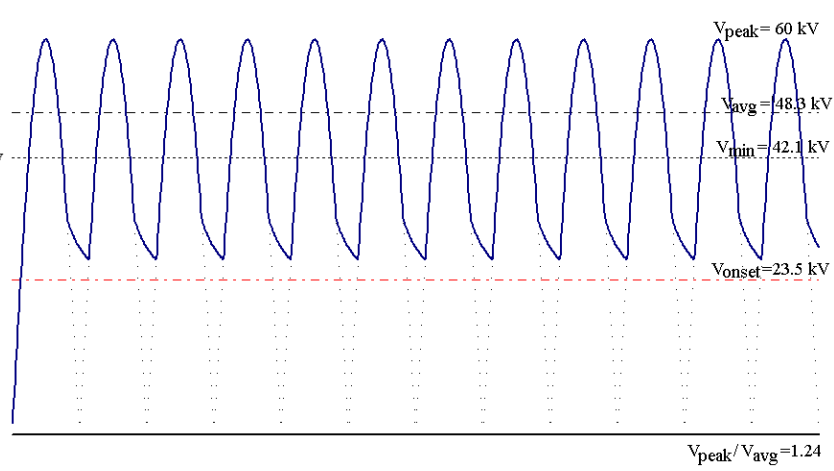

b.

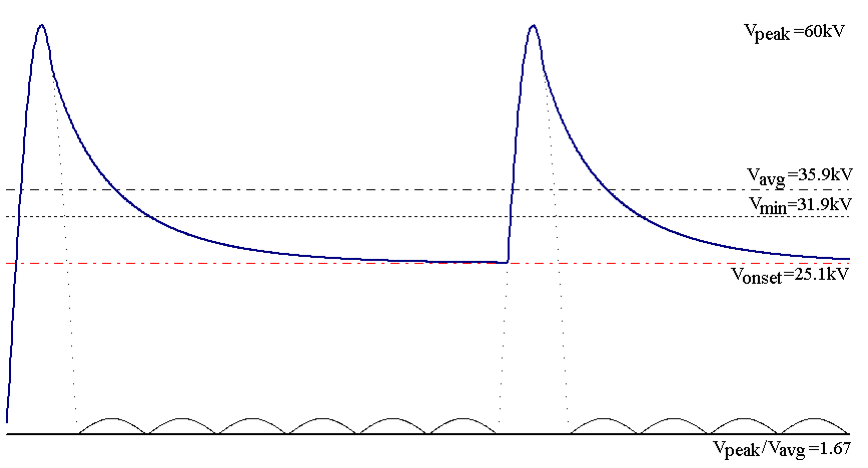

d.

Fig. 1. Voltage wave forms on the sections: a. continuous voltage; b. full-wave rectifier voltage; c. 3rd degree intermittent voltage; $d$. 7 th degree intermittent voltage 
Table 2.

Form factor [-] of voltage supply - simulations

\begin{tabular}{|l|c|c|c|c|}
\hline & $\begin{array}{c}\text { Continuous } \\
\text { voltage }\end{array}$ & $\begin{array}{c}\text { Full-wave } \\
\text { rectifier } \\
\text { voltage }\end{array}$ & $\begin{array}{c}\text { Intermittent } \\
\text { voltage with 3 } \\
\text { degree }\end{array}$ & $\begin{array}{c}\text { Intermittent } \\
\text { voltage with 7 } \\
\text { degree }\end{array}$ \\
\hline Section 1 & 1.023 & 1.242 & 1.455 & 1.669 \\
\hline Section 2 & 1.014 & 1.212 & 1.48 & 1.801 \\
\hline Section 3 & 1.015 & 1.215 & 1.492 & 1.858 \\
\hline
\end{tabular}

In the same simulation, it was considered the same shape of applied voltage on the precipitator sections. In the sections the voltages are: $44 \mathrm{kV}$ for the first section, $44 \mathrm{kV}$ for the second section, $36 \mathrm{kV}$ for the last section. After adjustment - automatic adjustment, voltages were tuned automatically to other values (in principle, around those imposed). The average voltages decrease, with the increasing of pulses (Figs.1.a-1.d). For voltages shown in Figs.1.a-1.d the electrodes are without dust, the resistivity of the dust was considered to be $10^{10} \Omega \cdot \mathrm{m}$ (high resistive, as ashes arising from coal burning). This leads to a lower consumption of electricity, with the decrease in the number of pulses (increasing intermittence degree). Peak voltage and the onset Corona voltage are about the same for all cases.

The ratio between the maximum and average voltage (form factor) is bigger, with increasing order of intermittence (Table 2). Operating voltages, on the sections are presented in Table 3. The voltage decreases with increasing order of intermitance. Voltages are highest in input section, and the lowest in the last section (and the same evolution with currents). Currents through sections decrease if the intermittance increases. The currents are lower in the last section (Table 3). The amount of dust will be mostly gathered by the first section. It seems like the use of full-wave rectifier voltages, causes the worst dust collection efficiency.

Simulations have been made depending on the distribution of dust particles, at the input and the output of precipitator, depending on the number and the weight and depending on the voltage shape. At the input, small diameter particles are in larger number, and larger diameter particles have bigger weight. After filtration, to the output, there was a shift towards the left (depending on the number and the mass of dust particles).

Table 3.

Electrical parameters, on sections, for different types of voltage supply - simulations

\begin{tabular}{|c|c|c|c|c|c|}
\hline & Parameters & $\begin{array}{l}\text { Conti- } \\
\text { nuous } \\
\text { voltage }\end{array}$ & $\begin{array}{l}\text { Full-wave } \\
\text { rectifier } \\
\text { voltage }\end{array}$ & $\begin{array}{l}\text { 3rd degree } \\
\text { intermittent } \\
\text { voltage }\end{array}$ & $\begin{array}{l}\text { 7th degree } \\
\text { intermittent } \\
\text { voltage }\end{array}$ \\
\hline \multirow{3}{*}{$\begin{array}{c}\text { Section } \\
1\end{array}$} & Voltage $[\mathrm{kV}]$ & 48.6 & 48.3 & 41.2 & 35.9 \\
\hline & Currents [A] & 8.594 & 1.604 & 1.511 & 0.086 \\
\hline & Onset Corona voltage $[\mathrm{kV}]$ & 25.2 & 25.2 & 33.2 & 31.9 \\
\hline \multirow{3}{*}{$\begin{array}{c}\text { Section } \\
2\end{array}$} & Voltage $[\mathrm{kV}]$ & 40.1 & 39.1 & 40.5 & 33.3 \\
\hline & Currents [A] & 3.048 & 3.331 & 1.823 & 0.099 \\
\hline & Onset Corona voltage [kV] & 29.3 & 29 & 32.3 & 28.9 \\
\hline \multirow{3}{*}{$\begin{array}{c}\text { Section } \\
3\end{array}$} & Voltage $[\mathrm{kV}]$ & 39.1 & 38.2 & 40.2 & 32.3 \\
\hline & Currents [A] & 3.028 & 3.117 & 1.945 & 0.103 \\
\hline & Onset Corona voltage $[\mathrm{kV}]$ & 28.3 & 28.2 & 31.7 & 27.7 \\
\hline
\end{tabular}




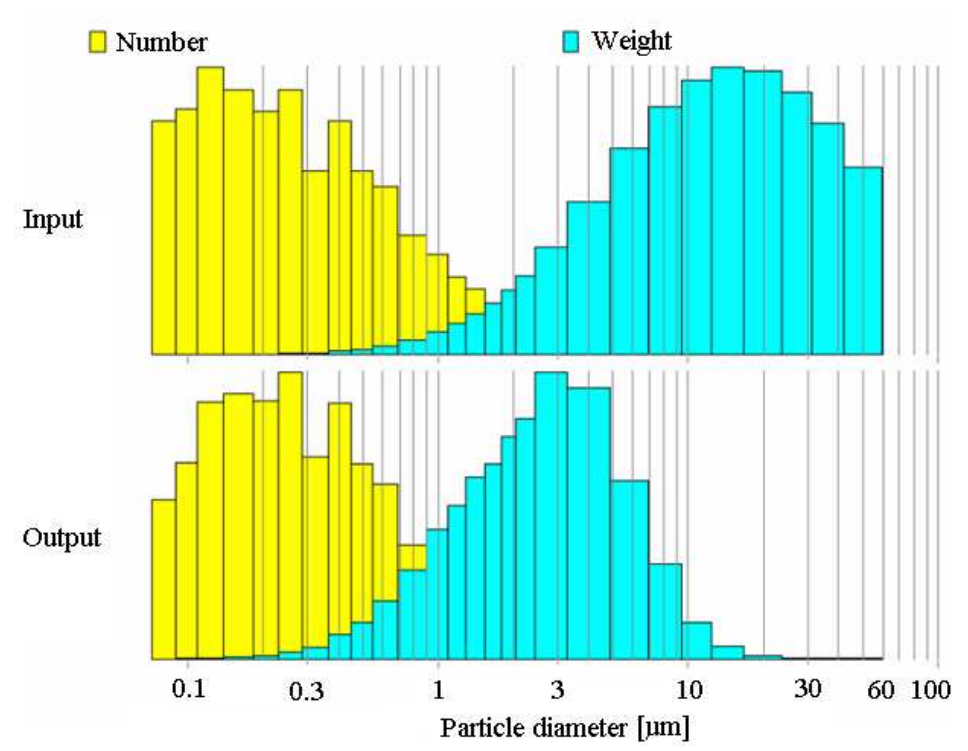

Fig. 2. Distribution of dust particles at the input and the output of precipitator, depending on the number and weight of dust particles, full-wave rectifier - simulations

At the input, the largest weight of dust particles are those with diameters ranging from 3 to 60 $\mu \mathrm{m}$, and the largest number of dust particles are those with diameters less than $3 \mu \mathrm{m}$. After collecting dust, the most dust particles are particles with diameters ranging between 1-10 $\mu \mathrm{m}$, and the largest number of dust particles are particles with diameters less than $1 \mu \mathrm{m}$ (Fig.2).

Particle collection efficiency for a precipitator is the most important parameter. In Tables 4 and 5 , the collection efficiency was simulated. It increases with increasing of intermittence. So, in intermittence supply with higher degree of intermittence, due, in principle, better collection efficiency by $1 \%$ compared with classical energization. The other sizes from table 5 (the penetration of dust particles, dust concentration at the output, the concentration of dust to the output for PM 10 - particles $10 \mu \mathrm{m}$, concentration from the output for PM 2.5 - particles $2.5 \mu \mathrm{m}$ ) have a reverse evolution. The concentration of dust particles with diameter less than $10 \mu \mathrm{m}$ is up to hundreds $\mathrm{mg} / \mathrm{m}^{3}$, and the concentration of dust particles with diameters below $2.5 \mu \mathrm{m}$ is up to tens of $\mathrm{mg} / \mathrm{m}^{3}$. The precipitators being very large, collection efficiency is high.

For industrial ESPs, using the intermittence power supplies may improve collection efficiency up to $1 \%$ comparable with SCR power supplies, for both shacking and not shacking sections.

Table 4.

Dust particles collection for different types of voltages, when sections are shacking - simulations

\begin{tabular}{|l|c|c|c|c|}
\hline \multicolumn{1}{|c|}{ Parameters } & $\begin{array}{c}\text { Continuous } \\
\text { voltage }\end{array}$ & $\begin{array}{c}\text { Full-wave } \\
\text { rectifier } \\
\text { voltage }\end{array}$ & $\begin{array}{c}\text { 3rd degree } \\
\text { intermittent } \\
\text { voltage }\end{array}$ & $\begin{array}{c}7 \text { th degree } \\
\text { intermittent } \\
\text { voltage }\end{array}$ \\
\hline Collecting efficiency [\%] & 94.41 & 95.77 & 97.18 & 97.79 \\
\hline Penetration of dust particles [\%] & 5.59 & 4.23 & 2.82 & 2,21 \\
\hline Output dust concentration $\left[\mathrm{mg} / \mathrm{m}^{3}\right]$ & 516.36 & 391.38 & 261.06 & 203.86 \\
\hline Output dust conc. for PM $10\left[\mathrm{mg} / \mathrm{m}^{3}\right]$ & 237.15 & 182.28 & 122.97 & 94.67 \\
\hline Output dust conc. for PM $2.5\left[\mathrm{mg} / \mathrm{m}^{3}\right]$ & 61.03 & 52.28 & 41.71 & 31.92 \\
\hline
\end{tabular}


Table 5.

Dust particles collection for different types of voltages, when sections are not shacking simulations

\begin{tabular}{|l|c|c|c|c|}
\hline \multicolumn{1}{|c|}{ Parameters } & $\begin{array}{c}\text { Continuous } \\
\text { voltage }\end{array}$ & $\begin{array}{c}\text { Full-wave } \\
\text { rectifier } \\
\text { voltage }\end{array}$ & $\begin{array}{c}\text { 3rd degree } \\
\text { intermittent } \\
\text { voltage }\end{array}$ & $\begin{array}{c}\text { 7th degree } \\
\text { intermittent } \\
\text { voltage }\end{array}$ \\
\hline Collecting efficiency [\%] & 96.31 & 97.24 & 98.17 & 98.67 \\
\hline Penetration of dust particles [\%] & 3.69 & 2.76 & 1.83 & 1.33 \\
\hline Output dust concentration $\left[\mathrm{mg} / \mathrm{m}^{3}\right]$ & 341.46 & 255.2 & 169.23 & 123.08 \\
\hline Output dust conc. for PM $10\left[\mathrm{mg} / \mathrm{m}^{3}\right]$ & 165.11 & 125.5 & 85.06 & 61.93 \\
\hline Output dust conc. for PM $2.5\left[\mathrm{mg} / \mathrm{m}^{3}\right]$ & 60.46 & 51.74 & 41.28 & 31.55 \\
\hline
\end{tabular}

\section{Improving Collection Efficiency Using a New Section}

The operation of some plate-type ESPs (with two, three, and four sections) from a thermoelectric power plant (S.C. Electrocentrale Deva S.A., Mintia, Romania) has been analyzed.

If $\varepsilon_{\mathrm{i}}$ is the relative weight for a certain average diameter of dust particle $\mathrm{d}_{\mathrm{i}}$, and $\mathrm{i}$ is the number of average diameters of dust particle resulted by analysis, then the average diameter of the dust particle $\mathrm{d}_{\mathrm{avg}}$ collected by a certain section of the ESP is [10]:

$$
\mathrm{d}_{\mathrm{avg}}=\frac{\sum_{\mathrm{i}=1}^{\mathrm{n}} \varepsilon_{\mathrm{i}} \cdot \mathrm{d}_{\mathrm{i}}}{100} \text {. }
$$

For an ESP with two sections the collected dust particles have diameters in the order of $\mu \mathrm{m}$; the inlet section (section 1) collects better the dust particles with diameters (above $10 \mu \mathrm{m}$ ), and the outlet section (section 2) collects dust particles with smaller diameter (below $10 \mu \mathrm{m}$ ).

The power supplies of ESPs with two and three sections ESPs were SCR types, with analogue of the current inside precipitators.

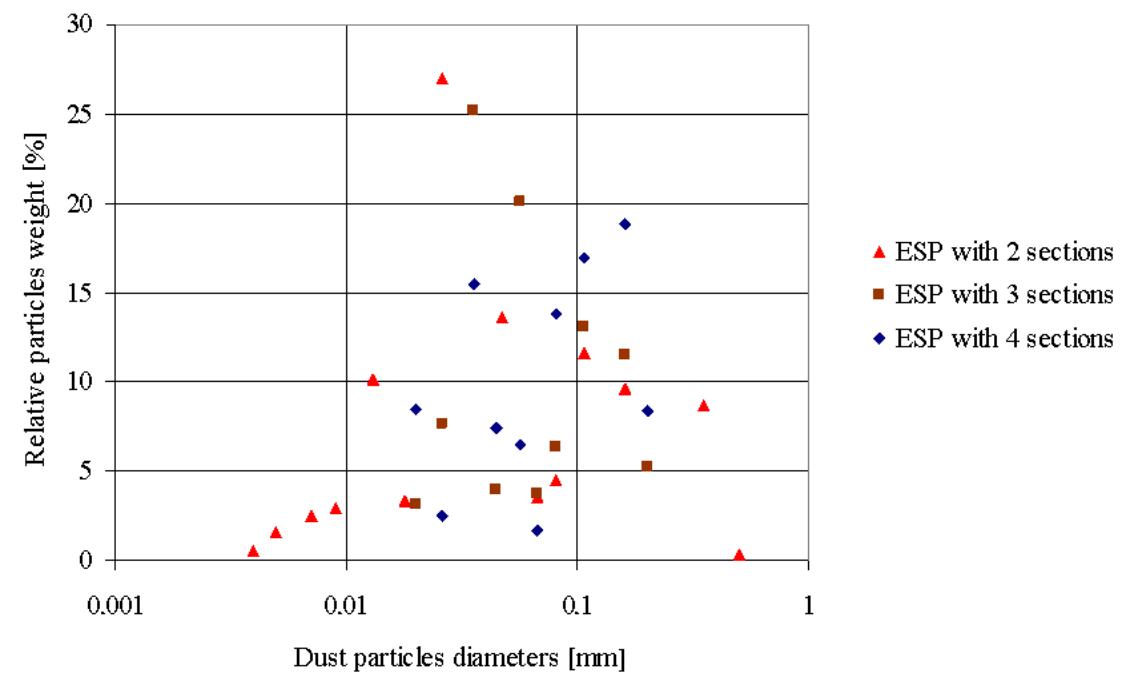

Fig. 3. Grainy fraction distributions of the collected dust particles, for the first section of different ESP - measure values 


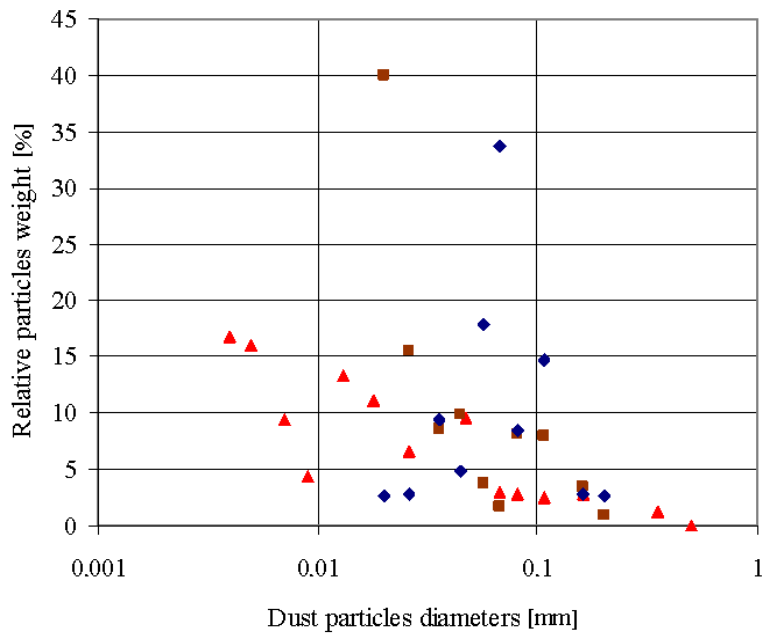

$\triangle$ ESP with 2 sections

- ESP with 3 sections

- ESP with 4 sections

Fig. 4. Grainy fraction distributions of the collected dust particles, for the second section of different ESP- measure values

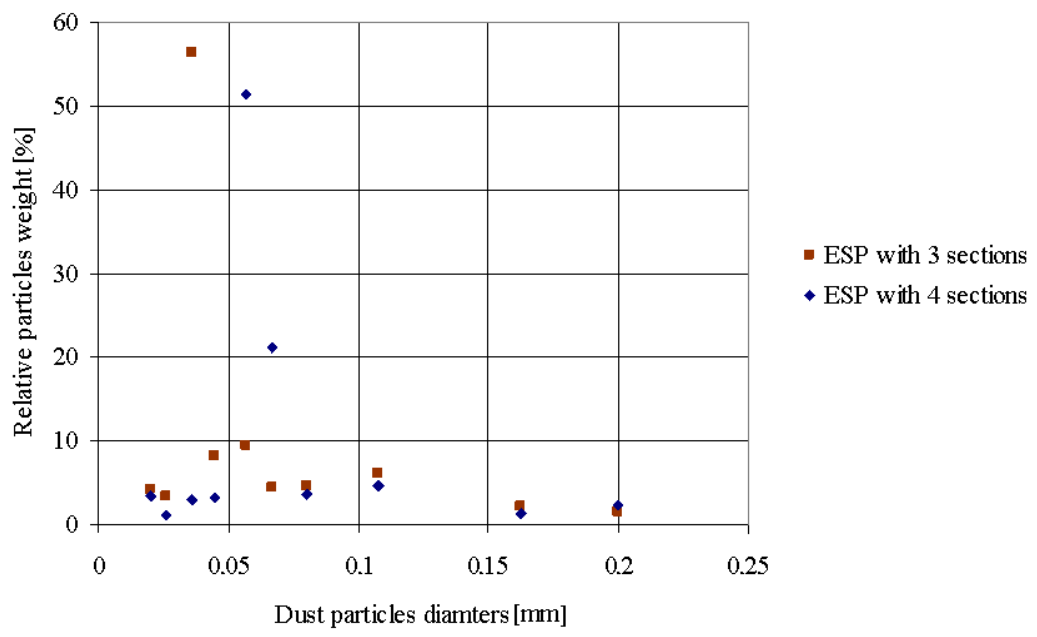

Fig. 5. Grainy fraction distributions of the collected dust particles, for the third section of different ESP- measure values

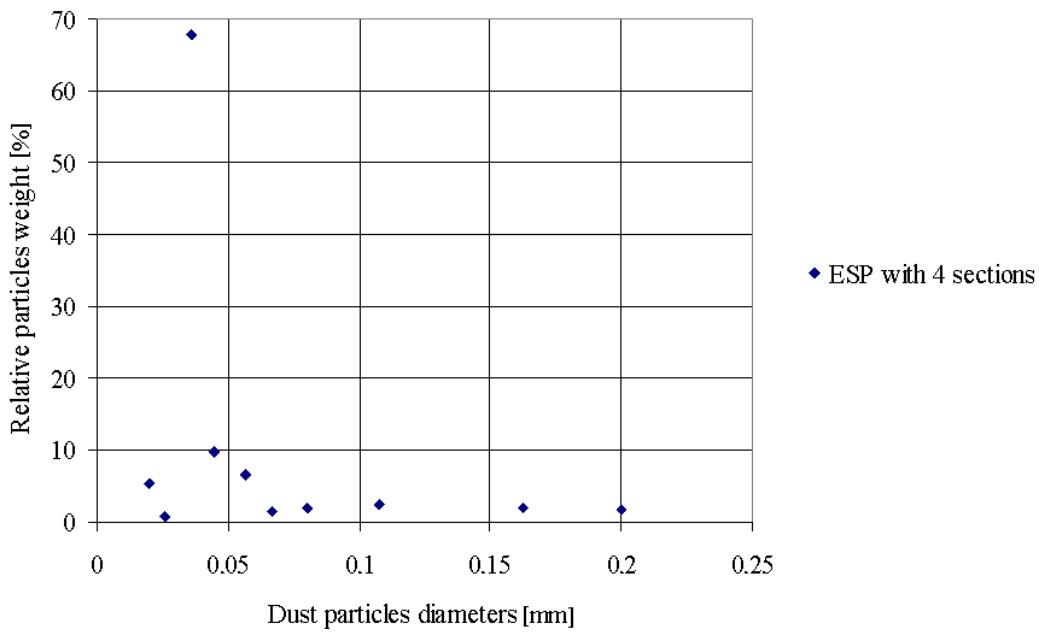

Fig. 6. Grainy fraction distributions of the collected dust particles, for the fourth section of different ESP- measure values 
Table 6.

Electrical parameters for ESP 1A with four sections - measure values

\begin{tabular}{|l|c|c|c|c|}
\hline & Sect. no. & $\mathrm{U}_{2 \min }[\mathrm{kV}]$ & $\mathrm{U}_{2 \max }[\mathrm{kV}]$ & $\mathrm{J}_{2 \max }\left[\mathrm{mA} / \mathrm{m}^{2}\right]$ \\
\hline Case 1 & 1 & 31 & 47 & 0.167 \\
\cline { 2 - 5 } & 2 & 28 & 43 & 0.111 \\
\cline { 2 - 5 } & 3 & 24 & 39 & 0.13 \\
\cline { 2 - 5 } & 4 & 18 & 44 & 0.37 \\
\hline Case 2 & 1 & 31 & 47 & 0.222 \\
\cline { 2 - 5 } & 2 & 29 & 47 & 0.24 \\
\cline { 2 - 5 } & 3 & 25 & 46 & 0.296 \\
\cline { 2 - 5 } & 4 & 19 & 43 & 0.351 \\
\hline
\end{tabular}

Table 7.

Electrical parameters for ESP 1B with four sections - measure values

\begin{tabular}{|l|c|c|c|c|}
\hline & Sect. no. & $\mathrm{U}_{2 \min }[\mathrm{kV}]$ & $\mathrm{U}_{2 \max }[\mathrm{kV}]$ & $\mathrm{J}_{2 \max }\left[\mathrm{mA} / \mathrm{m}^{2}\right]$ \\
\hline Case 1 & 1 & 41 & 45 & 0.037 \\
\cline { 2 - 5 } & 2 & 32 & 48 & 0.148 \\
\cline { 2 - 5 } & 3 & 26 & 40 & 0.111 \\
\cline { 2 - 5 } & 4 & 19 & 38 & 0.24 \\
\hline Case 2 & 1 & 38 & 46 & 0.055 \\
\cline { 2 - 5 } & 2 & 31 & 49 & 0.203 \\
\cline { 2 - 5 } & 3 & 26 & 43 & 0.203 \\
\cline { 2 - 5 } & 4 & 20 & 37 & 0.24 \\
\hline
\end{tabular}

For ESPs with three and four sections it is noticed that the dust particles collection, with the greatest weight, is made in the inlet section (section 1), then in the intermediary section (section 2 for precipitator with three sections, or section 2 and 3 for precipitator with four sections) and, the last (section 3 for precipitator with three sections, or section 4 for precipitator with four sections), in the outlet section where are collected particles with diameters smaller than $10 \mu \mathrm{m}$ (Figs.3-6).

The power supplies of ESPs with four sections were SCR types with digital control of the current inside sections.

Further, is analyzed the ESP with four sections. In Tables 6 and 7, $\mathrm{U}_{2 \min }$ represents the onset Corona voltage in section, and $U_{2 \max }$ the discharge voltage in the section. The current density $\mathrm{J}_{2 \max }$ corresponds to $U_{2 \max }$. Measures from groups of Tables 6 and 7 were made to four sections ESPs $(1 \mathrm{~A}$ and $1 \mathrm{~B})$ at different times. The onset Corona voltage $U_{2 \min }$ is increasingly smaller from the inlet sections (section 1) towards the outlet sections (section 4, Tables 6 and 7). Approximately the same evolution has also the discharge voltage $U_{2 \max }$. The current density is of hundreds of $\mu \mathrm{A} / \mathrm{m}^{2}$.

The dust particles with smallest diameters are collected by the ESP's outlet sections. The highest particle quantity is collected by the inlet sections (sections 1 and 2, Fig.3). The dust particles' diameter is below $0.3 \mathrm{~mm}$. Usually, the last section collects the dust particles with the smallest diameters.

In fig.7 the experimental data are represented graphically the average collecting efficiencies obtained in various situations, for many experimental data (tens of cases), depending on the number of ESPs sections: 2, 3, or 4 sections. The lowest collecting efficiency was obtained when using an ESP with 2 sections. Even if used modern control current power supplies, SCR types, the ESPs have an inferior collecting efficiency then ESPs with 3 and 4 sections. 


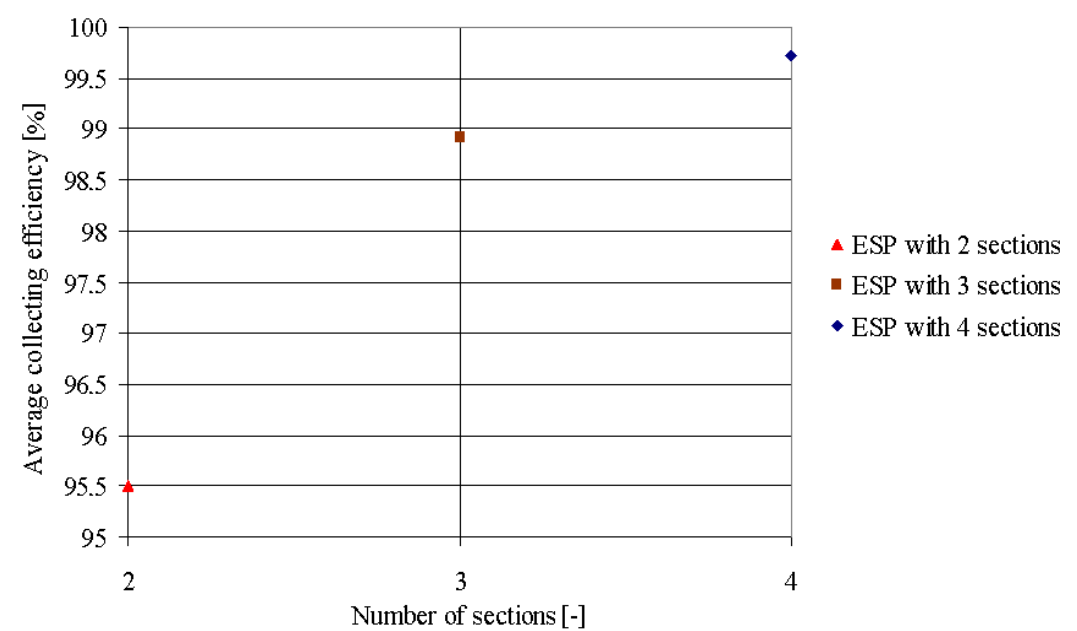

Fig. 7. Average collecting efficiency depends on the number of ESPs' sections-measure value

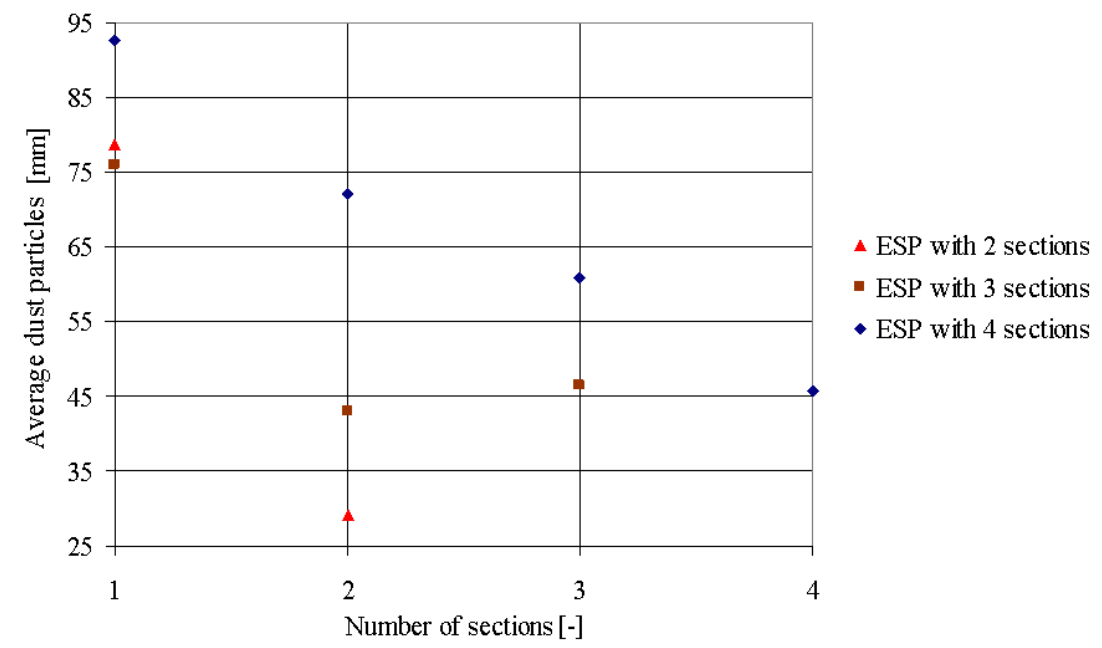

Fig. 8. Average dust particles diameter collected on each section in part (section 1,2,3, or 4), depending on the ESP's type: with 2,3, or 4 sections - measure values

When it is used ESPs with four sections, is registered a slight increase $(0.85 \%)$ in collecting of dust particles then in case when using ESPs with three sections.

The average diameter of the dust particles collected on sections, when using ESPs with 2, 3, and 4 sections is presented in fig. 8 . The dust particles, collected with the ESPs with the fewest sections ( 2 section), have diameters slightly smaller than the ESPs with more sections (3 or 4). Also, the differences are higher between the diameters of the dust particles collected with the ESPs with fewer sections against the ESPs with more sections. The dust particles, in principle, are collected by the inlet sections and the ones with smaller diameters in the sections from the ESP's outlet.

\section{Conclusions}

When upgrading an ESP is accomplished (i.e. changing the power supplies types or upgrading from three sections to four sections) must be done a technical and economic analysis. Adding a new section is an expensive solution (sometimes hundreds of thousands of Euros). Sometimes, after upgrading there isn't a remarkable improvement in the collecting efficiency.

Another solution is to upgrade the power sources of sections (other types of wave shape applied on sections) and automation (other control methods). Using a wet output section (a film of water flows on the surface collectors) to collect particles of dust particles with small diameters can be another solution. In both cases, the overall collection efficiency increasing up to $1 \%$, that means a consistent improvement for industrial ESPs that treat large gas flow. 


\section{Acknowledgment}

This paper was supported by the project "Development and support of multidisciplinary postdoctoral programmes in major technical areas of national strategy of Research - Development Innovation" 4D-POSTDOC, contract no. POSDRU/89/1.5/S/52603, project co-funded by the European Social Fund through Sectoral Operational Programme Human Resources Development 2007-2013.

\section{References}

[1] N. Plaks, Improving Collection of Toxic Fine Particles in ESPs, the $\mathrm{VI}^{\text {th }}$ International Conference on Electrostatic Precipitation, Budapest, Hungary, June 17-25, (1996), 6 pp.

[2] K.R. Parker, Applied Electrostatic Precipitation, Chapman and Hall, London, U.K., 1997.

[3] G.N. Popa, V. Vaida, C. Abrudean, S.I. Deaconu, I. Popa, A Case Study of ESP Electrical Characteristics from a Thermal Power Station, IEEE $44^{\text {th }}$ IAS Annual Meeting, Houston, Texas, U.S.A., Oct. 4-8 (2009), 6 pp.

[4] E. Kuffel, W.S. Zaengl, J. Kuffel, High Voltage Engineering. Fundamentals, Linacre House, Jordan Hill, Oxford, U.K., 2000.

[5] K. Parker, N. Plaks, Electrostatic Precipitator (ESP) Training Manual, United States Environmental Protection Agency, EPA-600/R-04-072, U.S.A., July, 2004.

[6] G. Zhang, X. Xie, J. Guo, J. Li, J. Lian, The Development and Application of an Energy Saving System Based on the Optimal Control and Multi-Parameter Feedback, the $X^{\text {th }}$ Int. Conf. on Electrostatic Precipitation (ICESP), Hangzhou, China, October 20-25 (2008), 328331.

[7] N.V.P.R. Prasad and other, Automatic Control and Management of Electrostatic Precipitator, IEEE Trans. on Ind. Appl., vol. 35, no. 3, May/June (1999), pp.561-567.

[8] V. Arrondel, G. Bacchiega, I. Gallimberti, ESP Modelling: from University Studies to Industrial Application, ICESP VIII, Birmingham, Alabama, USA, May 14-17 (2001), 1-7.

[9] N. Grass, W. Hartmann, M. Klöckner, Application of Different Types of High-Voltage Supplies on Industrial Electrostatic Precipitators, IEEE Trans. on Ind. Appl., vol.40, no.6, Nov./Dec. (2004), 1513-1520.

[10] G.N. Popa, V. Vaida, S.I. Deaconu, I. Şora, An Analysis on the Optimal Fields Number of the Plate-Type Electrostatic Precipitators Used in a Thermoelectric Power Plant, $12^{\text {th }}$ Int. Conf. on Optim. of Electrical and Electronic Equip., OPTIM (2010), Braşov, Romania, 232-239. 